${ }^{34}$ Hooper, R S, McGregor, J M, and Nathan, P W, fournal of Mental Sciences, 1945, 91, 458.

35 Pratt, R T C, and McKenzie, W, Lancet, 1958, 2, 347.

${ }^{36}$ Davison, K, and Bagley, C R, in Current Problems in Neuropsychiatry, ed R N Herrington, p 113. Ashford, Headley Brothers, 1969.

37 Turner, J W A, Brain, 1943, 66, 140.

${ }^{38}$ Hooper, R S, British fournal of Surgery, 1951, 39, 126.

${ }^{39}$ Mealey, J, Pediatric Head Injuries. Springfield, Illinois, C C Thomas, 1968.

40 Porter, R J, and Miller, R A, Fournal of Neurology, Neurosurgery, and Psychiatry, 1948, 11, 258.

41 Orthner, H, and Meyer, E, Acta Neurovegetativa, 1967, 30, 216.

42 Walker, A E, and Erculei, F, Head Injured Men Fifteen Years Later. Springfield, Illinois. C C Thomas, 1969.

43 Caveness, W F, fournal of Neurosurgery, 1963, 20, 570.
${ }^{44}$ Kay, W K, Beamish, P, and Roth, M, British fournal of Psychiatry, 1964, $110,146$.

45 Daghighian, I, Schweizer Archiv für Neurologie, Neurochirurgie und Psychiatrie, 1973, 112, 399.

${ }^{46}$ Field, J H, Epidemiology of Head Injuries in England and Wales. London, HMSO, 1976.

${ }^{47}$ Higashi, K, et al, fournal of Neurology, Neurosurgery, and Psychiatry, 1977, 40, 876.

48 Gammie, J W, personal communication, 1977.

49 Ingvar, D H, in Outcome of Severe Damage to the Central Nervous System, ed R Porter and D W Fitzsimons. Amsterdam, Elsevier, Excerpta Medica, 1975.

${ }^{50}$ Registrar General's Statistical Review of England and Wales, Part 1 Tables, Medical. London, HMSO, 1960.

(Accepted 9 October 1979)

\title{
Has the mortality of male doctors improved with the reductions in their cigarette smoking?
}

\author{
P N LEE
}

British Medical fournal, 1979, 2, 1538-1540

\section{Summary and conclusions}

From 1951 to 1971 male doctors reduced their cigarette smoking more than did men in social classes I and II combined. In 1970-2, 665 male doctors died aged under 65 . Had they shown the same improvements in cause-specific death rates over the 20 years as men in classes $I$ and II, 699 deaths would have been expected. This "saving" of 34 deaths in the doctors comprised savings from coronary heart disease (83), stroke (16), and lung cancer (8) balanced by 60 "losses" from three stress-related causes-namely, accidents, poisonings, etc (30); suicide (26); and cirrhosis of the liver (4)-plus 13 from other causes. As a relative reduction in mortality from heart disease in doctors (as compared with that in social classes I and II) also occurred during 1931-51-that is, before they began to give up smoking-some of the saving in heart-disease deaths in 1951-71 was probably not related to changes in smoking habits. The relative worsening in mortality from stressrelated diseases may have been due partly to a possible adverse effect of giving up smoking if smoking had acted to reduce stress.

From these findings, the benefits of giving up smoking may not be so great as has commonly been assumed.

\section{Introduction}

Cigarette smokers who stop smoking are claimed to run a smaller risk of dying than if they continue to smoke. ${ }^{2}$ Much evidence quoted to support this comes from studies in which ex-smokers have been shown to have death rates intermediate between those of people who have never smoked and those of continuing smokers. ${ }^{34}$ Such evidence, while consistent with a causal effect of giving up smoking, may also be explained in other ways. The sort of person who might stop smoking may differ from the sort of person who is likely to continue-for

Tobacco Advisory Council, London SW1E 5AG

$P$ N LEE, MA, research co-ordinator and statistician (now independent consultant in statistics, Cheam, Sutton) example, constitutionally ${ }^{5}$ - ${ }^{6}$ so that the differences observed in mortality may reflect differences other than smoking habits. That this explanation may have some substance was illustrated by a study showing that smokers who stopped smoking had, while they were still smoking, characteristics suggesting a substantially smaller risk of dying from coronary heart disease than comparable smokers who continued to smoke. ${ }^{7}$

Another way of trying to assess the effect on health of stopping smoking is to study whole populations who have greatly reduced their smoking and compare their trends in mortality with those of "otherwise similar" populations who have not. While not providing conclusive evidence (for which a randomised trial would be needed in which one group is forbidden to smoke while another continues to smoke), this method has fewer theoretical objections than the other type of study. Nevertheless, in such studies death rates from all diseases should be considered and not just those known to be smoking-related. If a person stops smoking he may do something else, and if this is hazardous to health the risk of other diseases, not necessarily conventionally related to smoking, may rise. This may be particularly important in high-need smokers, ${ }^{8}$ who may smoke to relieve stress. Smokers who smoke for physiological reasons are presumably less likely to stop than other smokers. Nevertheless, if such smokers are forced to give up by professional persuasion, legislation, or social pressure it is important to know whether their health is likely to benefit on balance.

British male doctors have reduced their smoking dramatically. This became clear from the study of Doll and Hill, ${ }^{9}$ in which 34440 men, representing $69 \%$ of all British doctors, completed smoking questionnaires at intervals from 1951 to 1971. In 1951 these doctors smoked on average $9 \cdot 1$ cigarettes a day-that is, $88 \%$ of the amount smoked by UK men of the same age. By 1971 the figure had fallen to 3.6 , which was only $37 \%$ of the national average. ${ }^{3}$ Their study also noted the cause and time of death of any doctor dying during the 20 years, and Doll and Peto $^{3}$ tested for several groups of causes of death whether the mortality of the doctors studied had improved relative to the population at large.

These workers found statistically significant reductions in death from lung cancer at all ages, ischaemic heart disease and myocardial degeneration at ages below 75 , and "other vascular causes associated with smoking" (including cerebral thrombosis) below the age of 65 . Although they noted that with regard to coronary heart disease they were "probably chiefly observing the secular tendency for decline in the standardised mortality ratio in social class $\mathrm{I}$, some of which may have been due to 
factors other than smoking habits," they concluded that "the trend was downwards for all of the major diseases that are believed to be caused by smoking." Nevertheless, their results suggested that the position of doctors had worsened for some groups of causes of death, especially "other non-vascular causes associated with smoking," which included cirrhosis of the liver and suicide (two causes for which doctors are known to have exceptionally high rates ${ }^{10}{ }^{11}$ ), but they gave no explanation for this. In fact, they did not comment on these adverse trends in doctors and gave no attention to the possibility that what doctors did instead of smoking may have been harmful.

With the publication of the Registrar General's latest occupational mortality tables for England and Wales (for 1970-2) ${ }^{12}$ I decided to re-examine the mortality trends in men. I restricted attention to men under 65 , as appropriate data were available only for this age group. While many doctors' deaths would thus be excluded, the relative mortality of smokers to nonsmokers is more pronounced in younger age groups, and any effect of giving up smoking might be seen most clearly in this group.

\section{Methods and results}

Table I gives for 1949-53 and 1970-2 the numbers of deaths from nine causes observed $(\mathrm{O})$ in doctors aged under 65 together with those expected $\left(E_{1}\right)$ from the male population as a whole. Multiplying the ratio $\mathrm{O}: \mathrm{E}_{1}$ by 100 gives the (age-) standardised mortality ratio (SMR). This measures the degree to which death rates in doctors were above or below the national average, which is taken as 100 . The two sets of figures, which were extracted from the Registrar General's data, ${ }^{1012}$ are unavoidably based on different definitions of causes of death in the different periods (see Appendix) owing to changes in the ICD. Nevertheless, these differences should not invalidate the comparisons made between the two periods, which were chosen to span a period similar to that considered by Doll and Peto.

In both periods doctors had relatively low death rates from lung cancer and bronchitis and relatively high death rates from suicide and cirrhosis of the liver (table I). Though the SMR fell for the first three causes of death-which correspond roughly to the three in which Doll and Peto noticed improvement-it rose for several others. Table II shows these contrasting trends more clearly by comparing the observed numbers of deaths from each cause in 1970-2 with those expected $\left(E_{2}\right)$ had the SMR remained as it was in 1949-53. "Saving" is a negative value of $\mathrm{O}$ minus $\mathrm{E}_{2}$-that is, the number of extra deaths

TABLE I-Observed $(O)$ and expected $\left(E_{1}\right)$ numbers of deaths from various causes among doctors aged under 65 during 1949-53 and 1970-2. Age-standardised mortality ratios $(S M R)$ calculated as (ratio of $O$ to $\left.E_{1}\right) \times 100$

\begin{tabular}{lrrrrrrrr}
\hline \multirow{2}{*}{ Cause of death } & \multicolumn{3}{c}{$1949-53$} & & \multicolumn{3}{c}{$1970-2$} \\
\cline { 2 - 4 } \cline { 6 - 8 } & $\mathrm{O}$ & $\mathrm{E}_{1}$ & $\mathrm{SMR}$ & & $\mathrm{O}$ & $\mathrm{E}_{1}$ & SMR \\
\hline Coronary heart disease & 345 & 249 & 139 & & 261 & 305 & 86 \\
Stroke & 106 & 76 & 140 & & 44 & 54 & 81 \\
Lung cancer & 46 & 92 & 50 & & 31 & 97 & 32 \\
Other malignant tumours & 131 & 165 & 79 & & 106 & 128 & 83 \\
Bronchitis & 18 & 76 & 24 & & 13 & 45 & 29 \\
Cirrhosis of liver & 12 & 5 & 240 & & 14 & 5 & 311 \\
Suicide & 61 & 27 & 226 & & 55 & 16 & 335 \\
Accidents, poisonings, etc & 42 & 61 & 69 & & 60 & 47 & 128 \\
All other causes & 247 & 378 & 65 & & 81 & 124 & 65 \\
\hline \multicolumn{1}{c}{$\quad$ Total } & 1008 & 1129 & 89 & 665 & 821 & 81 \\
\hline \multicolumn{1}{c}{} & & & & & &
\end{tabular}

TABLE II-Observed $(O)$ numbers of deaths from each cause in 1970-2 and expected $\left(E_{2}\right)$ numbers had standardised mortality ratios remained at 1949-53 values. "Savings" represent negative values of $\mathrm{O}-\mathrm{E}_{2}$ and "losses" positive values of $\mathrm{O}-\mathrm{E}_{2}$

\begin{tabular}{lrrrr}
\hline Cause of death & $\mathrm{O}$ & $\mathrm{E}_{2}$ & Saving & Loss \\
\hline Coronary heart disease & 261 & 423 & 162 & \\
Stroke & 44 & 75 & 31 & \\
Lung cancer & 31 & 49 & 18 & \\
Other malignant tumours & 106 & 102 & & 4 \\
Bronchitis & 13 & 11 & & 2 \\
Cirrhosis of liver & 14 & 12 & & 19 \\
Suicide & 55 & 36 & & 28 \\
Accidents, poisonings, etc & 60 & 32 & & \\
All other causes & 81 & 81 & & 55 \\
\hline \multicolumn{1}{c}{ Total* } & 665 & 821 & 211 & \\
\hline
\end{tabular}

${ }^{*}$ Difference $=156$ net saving. that would have occurred had there been no change in SMR since 1949-53 - and "loss" a positive value of O minus $\mathrm{E}_{2}$.

A total of 156 deaths were saved in male doctors, which constituted $23 \%$ of all their deaths in 1970-2. This saving, however, was virtually identical with the saving in deaths from coronary heart disease. Much of the trend in coronary mortality is common to social class I and not specific to doctors, so it seemed sensible to look at trends in mortality of social class I men over the same period and compare them with trends in the mortality of doctors. Nevertheless, since there is no completely satisfactory way of comparing class I in 1949-53 with class I in 1970-2 $2^{13}$ I examined trends in classes I and II combined. Table III shows that for all three causes of death contributing substantially to the gain in numbers of deaths in doctors there was a definite fall in the SMR of men in classes I and II combined. Furthermore, for several causes in which doctors lost ground relative to the national average (see table II) the change in classes I and II men over the 20 years was more favourable than in doctors.

TABLE III-Observed $(O)$ and expected $\left(E_{1}\right)$ numbers of deaths from each cause among all men in social classes I and II combined during 1949-53 and 1970-2. Age-standardised mortality ratios (SMR) taken as 100

\begin{tabular}{|c|c|c|c|c|c|c|}
\hline \multirow{2}{*}{ Cause of death } & \multicolumn{3}{|c|}{$1949-53$} & \multicolumn{3}{|c|}{$1970-2$} \\
\hline & $\mathrm{O}$ & $E_{1}$ & SMR & $\mathrm{O}$ & $\mathrm{E}_{1}$ & SMR \\
\hline $\begin{array}{l}\text { Coronary heart disease } \\
\text { Stroke } \\
\text { Lung cancer } \\
\text { Other malignant tumours } \\
\text { Bronchitis } \\
\text { Cirrhosis of liver } \\
\text { Suicide } \\
\text { Accidents, poisonings, etc } \\
\text { All other causes }\end{array}$ & $\begin{array}{rl}21 & 989 \\
6 & 607 \\
5 & 971 \\
11 & 576 \\
3102 \\
580 \\
2342 \\
3304 \\
21770\end{array}$ & $\begin{array}{rl}20 & 077 \\
6 & 185 \\
7318 \\
12785 \\
6232 \\
360 \\
1987 \\
4245 \\
28385\end{array}$ & $\begin{array}{r}110 \\
107 \\
82 \\
91 \\
50 \\
161 \\
118 \\
78 \\
77\end{array}$ & $\begin{array}{rl}20 & 378 \\
3440 \\
4788 \\
8397 \\
1673 \\
455 \\
1093 \\
2680 \\
6734\end{array}$ & $\begin{array}{rl}22 & 874 \\
4 & 063 \\
7294 \\
9414 \\
3451 \\
332 \\
1166 \\
3663 \\
9237\end{array}$ & $\begin{array}{r}89 \\
85 \\
66 \\
89 \\
48 \\
137 \\
94 \\
73 \\
73\end{array}$ \\
\hline Total & 77241 & 87574 & 88 & 49638 & 61494 & 81 \\
\hline
\end{tabular}

The next step was therefore to compare the numbers of deaths observed in doctors with those expected $\left(E_{3}\right)$ had they shown the same improvement in SMR as men in classes I and II as a whole. $E_{3}$ is calculated as $\mathrm{O}$ multiplied by (SMR in classes I and II for 1970-2/SMR in classes I and II for 1949-53)/(SMR in doctors for 1970-2/SMR in doctors for 1949-53). Table IV gives the results. Savings and losses are calculated as for table II. Comparison of tables II and IV shows that the savings in the first three diseases were dramatically reduced and that the total saving was only 34 -that is, $5 \%$ of total deaths.

The comparison in table IV is relevant only if doctors had given up smoking to a considerably greater extent than had men in classes I and II. Though the data are not strictly comparable, it seems that

TABLE IV-Observed $(O)$ numbers of deaths from each cause in doctors during 1970-2 and expected $\left(E_{3}\right)$ numbers had doctors shown same improvement in standardised mortality ratios as men in social classes I and II as whole. "Savings" and "losses" calculated as in text and table II

\begin{tabular}{lrrrr}
\hline Cause of death & $\mathrm{O}$ & $\mathrm{E}_{\mathbf{s}}$ & Saving & Loss \\
\hline Coronary heart disease & 261 & 344 & 83 & \\
Stroke & 44 & 60 & 16 & \\
Lung cancer & 31 & 39 & 8 & 6 \\
Other malignant tumours & 106 & 100 & & 3 \\
Bronchitis & 13 & 10 & & 4 \\
Cirrhosis of liver & 14 & 10 & & 26 \\
Suicide & 55 & 29 & & 30 \\
Accidents, poisonings, etc & 60 & 30 & & $\mathbf{4}$ \\
All other causes & 81 & 77 & & 73 \\
\hline \multicolumn{1}{c}{ Total* } & 665 & 699 & 107 & 73 \\
\hline
\end{tabular}

${ }^{*}$ Difference $=34$ net saving.

this was so. From the findings of Doll and Peto, ${ }^{3}$ who recorded the daily cigarette consumption of doctors in various age groups, doctors under 65 smoked $9 \cdot 1$ cigarettes daily in 1951, 8.2 daily in 1956, and 3.7 daily in 1971 - an overall reduction of $59 \%$. Todd ${ }^{14}$ gave data on weekly consumption by social class, but only back to 1958 . If we average the figures for 1970-2 the consumption in classes I and II combined was 62 cigarettes a week, which is $21 \%$ less than the figure (78) for 1958 and 1961 combined. For earlier years Todd gave data only on the percentage of cigarette smokers by income groups. Between $1952(61 \%)$ and $1956(63 \%)$ little change occurred in the percentage of smokers in the most comparable income group, $\mathrm{A}$ and $\mathrm{B}$ combined. 


\section{Discussion}

During 1951-71 doctors apparently reduced their smoking much more than did men in social classes I and II. Over the same period doctors' mortality also relatively improved. The extent of this improvement was, however, not great (34 deaths saved) and not consistent over the various causes' of death considered. Indeed, there were substantial losses from two causes (suicide, 26; accidents, 30) that exceeded the savings from two of the smoking-related diseases (stroke, 16; lung cancer, 8). Only the saving of 83 deaths from heart disease made the overall saving positive. This saving, however, may have been only partly related to giving up smoking, as an improved trend of coronary heart disease in doctors relative to that in classes I and II was seen before 1951-that is, before doctors began to stop smoking. Indeed, between 1930-2 and 1949-53 the SMR for doctors fell from 167 to 139, whereas that for classes I and II rose from 107 to 110 , representing a saving of 78 deaths in 1949-53 that seem unlikely to have been attributable to changes in smoking habit.

Doctors in 1971 would have comprised far more men born in India, Pakistan, and Sri Lanka than those in 1951, and such doctors may have abnormally high death rates. ${ }^{12}$ I calculated savings and losses omitting these doctors from the 1971 figures, but this had little effect on the results, savings changing from 34 out of 665 to 30 out of 607 , with no pronounced effect on any specific cause of death.

Interestingly doctors incurred losses (totalling 60 deaths) from suicide, cirrhosis of the liver, and "accidents, poisonings, etc" -all of which may have been related to stress, especially since $35 \%$ of deaths from the third group were from accidental poisoning or accorded open verdicts that could also have been suicide. Doctors are susceptible to these causes of death, ${ }^{11} 15$ but discussion has previously centred on why death rates are high, not why they are increasing relative to other groups. There are three possibilities. Firstly, the stress of doctors may have been increasing more than in other occupations, perhaps related to the ramifications of the National Health Service. Secondly, the change to natural gas towards the end of the study period may have made it more difficult for the general population to commit suicide ${ }^{16}$ but scarcely affected doctors, who would normally use drugs. Thirdly-and not necessarily ruling out the first possibility-the removal of cigarette smoking, which may have alleviated stress, may have had some adverse effects on health. Admittedly, Doll and Peto ${ }^{3}$ did not find an exceptionally high death rate from these diseases in ex-smokers, but the relevance of this in discriminating between the possibilities mentioned above is dubious. Apart from the possibility that people who stop smoking differ in various ways from those who continue to smoke, not only would the ex-smokers have included some who stopped before smoking and health became an issue but some of the continuing smokers would be people who had reduced smoking or who smoked cigarettes with lower deliveries and who may no longer have found that cigarette smoking offered the protection against stress that it used to.
These findings may be taken only as suggestive; and, indeed, they may not be as relevant for the population at large, who may divert their stress into less lethal directions, as for doctors. Nevertheless, Khosla and Campbell ${ }^{17}$ observed that Swedish men smoke less heavily than Scotsmen but have a higher suicide and accidental poisoning rate. Those considering bringing pressure to bear on society to reduce smoking should keep in mind that, for some smokers at least, giving up smoking may have adverse consequences. In any case, the benefits to be gained may well be fewer than many sources would have us believe. ${ }^{12}$ The lack of evidence of any large benefit is strengthened by the finding ${ }^{18}$ in a randomised controlled trial that smokers persuaded-apparently successfully-to stop smoking had similar total death rates to a matched group of smokers who were not so persuaded.

Thanks are due to the Office of Population Censuses and Surveys for making available the data on doctors born in India, Pakistan, and Sri Lanka; and also to Dr John Fox, Dr Nicholas Wald, the former Human Smoking Sub-Committee of the Tobacco Research Council, and colleagues for helpful comments.

Correspondence should be addressed to: Mr P N Lee, 25 Park Road, Cheam, Sutton SM3 8PY.

\section{References}

1 Surgeon General, The Health Consequences of Smoking. Washington DC, Department of Health, Education and Welfare, 1975.

2 Royal College of Physicians, Smoking or Health. London, Pitman Medical, 1977.

${ }^{3}$ Doll, R, and Peto, R, British Medical fournal, 1976, 2, 1525.

4 Hammond, E C, in Epidemiological Study of Cancer and Other Chronic Diseases, National Cancer Institute Monograph No 19, p 1. Bethesda, Maryland, NIH, 1965.

${ }^{5}$ Fisher, R A, Smoking: The Cancer Controversy. Some Attempts to Assess the Evidence. Edinburgh, Oliver and Boyd, 1959.

${ }^{6}$ Burch, P R J, The Biology of Cancer. A New Approach. Lancaster, Medical and Technical Publishing, 1976.

7 Seltzer, C C, Fournal of the Royal Statistical Society, series A, 1978, 141, 463.

${ }^{8}$ McKennell, A C, A Comparison of Two Smoking Typologies, Tobacco Research Council Research Paper No 12. London, TRC, 1973.

${ }^{9}$ Doll, R, and Hill, A B, British Medical fournal, 1954, 1, 1451.

10 Registrar-General, Occupational Mortality, Decennial Supplement for England and Wales, 1951. London, HMSO, 1957.

${ }^{11}$ Murray, R M, Fournal of the Royal College of Physicians of London, 1978, 12, 403.

12 Office of Population Censuses and Surveys, Occupational Mortality, The Registrar-General's Decennial Supplement for England and Wales, 1970-2. London, HMSO, 1978.

13 Marmot, M G, et al, British Medical fournal, 1978, 2, 1109.

14 Todd, G F, Social Class Variations in Cigarette Smoking and in Mortality from Associated Diseases, Tobacco Research Council Occasional Paper No 2. London, TRC, 1976.

15 Grist, L, General Practitioner, 1978, 1, 16.

16 Adelstein, A M, and Mardon, C, Population Trends, 1975, 2, 13.

17 Khosla, T, and Campbell, H, Lancet, 1978, 1, 1355.

18 Rose, G A, and Hamilton, P J S, Fournal of Epidemiology and Community Health, 1978, 32, 275.

(Accepted 3 October 1979)

APPENDIX-ICD codes of diseases causing death in 1949-53 (7th revision) and 1970-2 (8th revision)*

\begin{tabular}{|c|c|c|c|c|}
\hline \multirow{2}{*}{ Group name } & \multicolumn{2}{|l|}{$1949-53$} & \multicolumn{2}{|l|}{$1970-2$} \\
\hline & Causes & Codes & Causes & Codes \\
\hline $\begin{array}{l}\text { Coronary heart disease } \\
\text { Stroke } \\
\text { Lung cancer } \\
\text { Other malignant tumours } \\
\text { Bronchitis } \\
\text { Cirrhosis of liver } \\
\text { Suicide } \\
\text { Accidents, poisonings, etc }\end{array}$ & 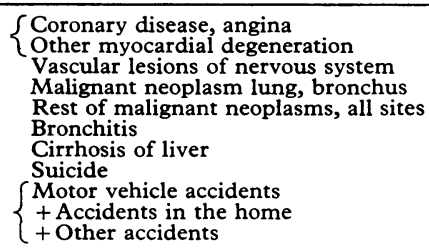 & $\begin{array}{l}420 \\
422 \\
330-334 \\
162-163 \\
140-161,164-205 \\
500-502 \\
581 \\
\text { E963, 970-979 } \\
\text { E810-835 } \\
\text { E870-936 } \\
\text { E800-962 }\end{array}$ & $\begin{array}{l}\text { Hypertensive disease } \\
\text { Ischaemic heart disease } \\
\text { Cerebrovascular disease } \\
\text { Malignant neoplasm trachea, bronchus, lung } \\
\text { Rest of malignant neoplasms } \\
\text { Bronchitis, emphysema, asthma } \\
\text { Cirrhosis of liver } \\
\text { Suicide } \\
\text { Accidents, poisonings, violence } \\
\text { Less suicide }\end{array}$ & $\begin{array}{l}400-404 \\
410-414 \\
430-438 \\
162 \\
140-161,163-209 \\
409-493 \\
571 \\
\text { E950-959 } \\
\text { E800-959 } \\
\text { E950-959 }\end{array}$ \\
\hline
\end{tabular}

* In 1930-2 coronary heart disease was defined as non-valvular heart disease (ICD 6th revision, 90, 91, 93, 94, 95). Definitions of coronary heart disease areas given by Marmo et al. ${ }^{13}$ 